\title{
Hormonal Regulation of Proton Secretion in Rabbit Medullary Collecting Duct
}

\author{
Steven Hays, Juha P. Kokko, and Harry R. Jacobson \\ Department of Internal Medicine, University of Texas Health Science Center, Dallas, Texas 75235
}

\begin{abstract}
With the exception of aldosterone, little is known about the hormonal regulation of distal nephron acidification. These experiments investigated the effects of prostaglandin $E_{2}$, indomethacin, lysyl-bradykinin, 8-bromo-cyclic AMP, and forskolin on proton secretion in the major acidifying segment of the distal nephron, the medullary collecting duct from inner stripe of outer medulla.

Using in vitro microperfusion and microcalorimetry, net bicarbonate reabsorption (proton secretion) was measured in rabbit medullary collecting ducts before, during, and after exposure to each test substance. PGE 2 reduced proton secretion $12.2 \%$, while the following substances stimulated proton secretion: indomethacin 14.2\%; 8-bromo-cyclic AMP 34.5\%; forskolin 39\%. Lysylbradykinin was without effect.

These studies demonstrate that distal nephron acidification, in addition to being stimulated by aldosterone, is significantly inhibited by the hormone PGE $_{2}$. The stimulation of proton secretion by cAMP suggests that other hormones known to activate adenylate cyclase may also influence distal nephron acidification.
\end{abstract}

\section{Introduction}

The distal nephron is important as the final determinant of urinary acidification (1-4). Acidification of the urine occurs in several distinct distal nephron segments including the distal convoluted tubule, cortical collecting tubule, medullary and papillary collecting ducts (5-10). The capacity for collecting duct proton secretion (or bicarbonate reabsorption) shows segmental differences. The rat distal convoluted tubule and the rabbit cortical collecting tubule possess a low capacity for acidification (5-8). In contrast, the medullary collecting tubule from the rabbit and rat secretes protons at a higher rate $(7-9,11)$. Several transport characteristics of the medullary collecting tubule make it an ideal segment to study the regulation of distal nephron acidification. These include no evidence for spontaneous net sodium or potassium transport (12); no evidence for bicarbonate secretion $(8,13)$; independence of proton secretion from sodium transport or from the presence of sodium in luminal and peritubular fluids $(7,14)$. With respect to active transport, the medullary collecting tubule thus appears to be involved exclusively in proton secretion.

Portions of this work were presented in 1985 before the National Meeting of the American Federation of Clinical Research, Washington, DC. This portion has appeared in abstract form in 1985. (Clin. Res. 35:585a.).

Address reprint requests to Dr. Hays.

Received for publication 13 February 1986.

J. Clin. Invest.

(C) The American Society for Clinical Investigation, Inc.

0021-9738/86/11/1279/08 \$1.00

Volume 78, November 1986, 1279-1286
Two categories of controlling influences may be important in considering the regulation of acidification by the medullary collecting duct. The first group of factors that may regulate acidification in this nephron segment is an alteration in pH (both respiratory and metabolic). Previous studies on medullary collecting duct acidification have already examined the effects of both in vivo and in vitro alterations in the acid-base status and environment of the rabbit and rabbit tubule $(8,13)$. The second broad category of potential regulatory factors includes a number of hormones or hormone messengers that are known to affect certain transport processes in the distal nephron. The most studied and best known of these hormonal regulatory factors is aldosterone, which has been shown to influence acidification in both cortical and medullary collecting tubules (14-17). Much less is known about the effects of other hormones or mediators of hormone action on distal nephron proton secretion. This study examines the effects of the prostaglandin $\mathrm{E}_{2}\left(\mathrm{PGE}_{2}\right)^{1}$ and lysylbradykinin on medullary collecting duct acidification. In addition, the effects of cyclic AMP, the common second messenger, were examined since a number of hormonal actions on epithelial cells involve alteration of intracellular levels of cyclic nucleotides.

\section{Methods}

\section{Microperfusion-general experimental features}

The technique of in vitro microperfusion was as previously described by Burg (18). Briefly, female New Zealand White rabbits weighing 1.5-2.5 $\mathrm{kg}$ were maintained on standard laboratory chow and tap water ad lib. Animals were decapitated and the left kidney rapidly removed, decapsulated, and sliced into 1-mm coronal slices. Slices were placed in oxygenated bathing solution at $4^{\circ} \mathrm{C}, \mathrm{pH} 7.40$. One perfusate and two bathing solutions were utilized in the protocols. The perfusate was an artificial plasma ultrafiltrate containing (in $\mathrm{mM}$ ) $\mathrm{NaCl}, 105 ; \mathrm{KCl}, 5 ; \mathrm{NaHCO}_{3}$, 25; $\mathrm{Na}$ acetate, $10 ; \mathrm{NaHPO}_{4}, 2.3 ; \mathrm{CaCl}_{2}, 1.2 ; \mathrm{MgSO}_{4}, 1$; glucose, 8.3; and alanine, 5. Bathing solutions in all experiments except those with lysyl-bradykinin contained 5\% vol/vol fetal calf serum. In protocols utilizing lysyl-bradykinin in the bathing solution, the bath was identical in composition except for $2.4 \mathrm{mM} \mathrm{CaCl}_{2}$ and $6 \mathrm{~g} / 100 \mathrm{ml}$ defatted bovine serum albumin (CRG-7, Armour Pharmaceutical Co., Kankakee, IL). Albumin was added instead of fetal calf serum to lessen lysyl-bradykinin metabolism. In protocols utilizing indomethacin, solutions were identical to those used in the lysyl-bradykinin experiments with $2.4 \mathrm{mM} \mathrm{CaCl}{ }_{2}$ and $6 \mathrm{~g} / 100 \mathrm{ml}$ defatted bovine serum albumin, but in addition 5\% vol/ vol fetal calf serum was present. Bathing solutions and perfusate were gassed at $37^{\circ} \mathrm{C}$ with $95 \% \mathrm{O}_{2} / 5 \% \mathrm{CO}_{2}$ to $\mathrm{pH} 7.35-7.40$ and drawn anaerobically into syringes for use. The dissection medium was made hypertonic (450 mosM) by addition of $\mathrm{NaCl}$ to facilitate tubule harvest. Segments of medullary collecting duct (MCD) from inner stripe of outer renal medulla $\left(\mathrm{OM}_{\mathrm{i}} \mathrm{CT}\right)$ were anatomically identified as previously described by Stone et al. (9). Tubules were transferred to a thermostatically

1. Abbreviations used in this paper: $\mathrm{ADH}$, antidiuretic hormone; CVP, constant volume pipette; DMSO, dimethyl sulfoxide; DOCA, desoxycorticosterone acetate; $J_{\mathrm{v}}$, net volume flux; mTALH, medullary thick ascending limb of Henle; $\mathrm{OM}_{\mathrm{i}} \mathrm{CT}$, inner stripe of outer renal medulla; $\mathrm{PGE}_{2}$, prostaglandin $\mathrm{E}_{2} ; V_{\mathrm{T}}$, transepithelial voltage. 
controlled lucite perfusion chamber and perfused between concentric glass pipettes at $37^{\circ} \mathrm{C}$. The tubular ends of each glass holding pipette contained elastomeric silicone resin (Sylgard 184, Dow Corning Corp., Midland, MI) to provide both an electrical and water seal. Perfusion rate was hydrostatically controlled to a rate of $1-3 \mathrm{nl} / \mathrm{min}$. Bathing solutions were constantly exchanged at $0.6 \mathrm{ml} \cdot \mathrm{min}^{-1}$ with an infusion pump (Sage Instruments, Div. Orion Research, Inc., Cambridge, MA). A perfusion pipette, centered in one of the holding pipettes, was advanced 50-100 $\mu \mathrm{m}$ into the tubule lumen. This pipette also served as an intraluminal electrode because it was connected via a Ringer's agarose bridge to a calomel half-cell. The circuit was completed by a similar agarose bridge placed in the perfusion chamber and connected to a second calomel halfcell. Transepithelial voltage $\left(V_{T}\right)$ thus was monitored continuously throughout the experiment. $V_{\mathrm{T}}$ was measured with a battery-operated electrometer (model 602, Keithley Instruments, Inc., Cleveland, $\mathrm{OH}$ ) and recorded on a strip-chart recorder (Rikadenki model B261, Soltec Corp., Sun Valley, CA). Timed samples of tubular fluid were collected in a constant volume pipette (CVP) under water-equilibrated mineral oil. This pipette was calibrated for each experiment as previously described by Schuster et al. (19).

Tubules were equilibrated for $60 \mathrm{~min}$ at $37^{\circ} \mathrm{C}$ before experimentation. Net volume absorption was determined by using exhaustively dialyzed methoxy $\left[{ }^{3} \mathrm{H}\right]$ inulin (New England Nuclear, Boston, MA) as a volume marker by the method of Schafer et al. (20). Net volume flux $\left(J_{v}\right)$ was calibrated from differences in $\left[{ }^{3} \mathrm{H}\right]$ inulin activity between perfused and collected fluid as previously described (21). Net total $\mathrm{CO}_{2}$ flux $\left(\mathrm{JHCO}_{3}\right)$ was determined by microcalorimetry and calculated according to the following equation (22): $J \mathrm{HCO}_{3}=V_{1}\left(\mathrm{C}_{1}-\mathrm{C}_{0}\right) / L$ where $V_{1}$ is the perfusion rate in $\mathrm{nl} / \mathrm{min}, C_{1}$ is the perfusate total $\mathrm{CO}_{2}, \mathrm{C}_{0}$ is the collected fluid total $\mathrm{CO}_{2}$, and $L$ is the tubule length in $\mathrm{mm}$. This equation assumes a negligible change in bicarbonate ion concentration due to water movement, which was substantiated by measuring $J_{\mathrm{v}}$ and discarding experiments in which $J_{\mathrm{v}} \geqq 0.05 \mathrm{nl} \cdot \mathrm{mm}^{-1} \cdot \mathrm{min}^{-1}$. Total $\mathrm{CO}_{2}$ measurements were made by collecting fluid into 30-50-nl CVPs that were then used to inject the sample into the phosphoric acid chamber of the picapnotherm. Each sample was compared to a paired injection of a $25-\mathrm{mM}$ $\mathrm{Na}_{2} \mathrm{CO}_{3}$ standard and the concentrations of the collected fluid were calculated. Three to six $\mathrm{JHCO}_{3}$ determinations were made with experimental maneuvers. The $J \mathrm{HCO}_{3}$ determinations were averaged for each experimental period and represent a single value for each experiment.

\section{Experimental protocols}

The general protocol was similar in all experiments. After an initial 60min equilibration period a control $J_{\mathrm{V}}$ and at least three $\mathrm{JHCO}_{3}$ determinations were made with vehicle present in the bath. The bath was then changed to one containing the test substance dissolved in vehicle. After a 30-min equilibration period, an experimental $J_{\mathrm{v}}$ and at least three $\mathrm{JHCO}_{3}$ determinations were obtained. In some protocols, a postexperimental period was performed to assess for recovery. Again, a 30min equilibration period was allotted prior to $J_{\mathrm{V}}$ and $\mathrm{JHCO}_{3}$ determinations.

Five experimental protocols were examined.

Effects of $P G E_{2}$. Control collections were obtained in a bathing solution containing vehicle $\left(95 \%\right.$ ethanol). $\mathrm{PGE}_{2}\left(10^{-6} \mathrm{M}\right)$ dissolved in 95\% ethanol and added to the bath was then tested. In some instances, an additional period was performed to assess recovery following the experimental period.

Effects of indomethacin. In a group of tubules harvested from normal animals control collections were obtained with a bathing solution containing vehicle (dimethyl sulfoxide [DMSO], $50 \mu 1 / 200-\mathrm{ml}$ bath). Following the control collections, indomethacin $\left(1.25 \times 10^{-4} \mathrm{M}\right)$ dissolved in DMSO was added to the bath and repeat collections were made. A second group of animals was surgically adrenalectomized and maintained on standard laboratory chow and $0.9 \%$ normal saline drinking water ad lib., 8-20 d prior to experimentation. Tubules were harvested from these animals and control collections were obtained with DMSO in the bath. Indomethacin $\left(5.0 \times 10^{-5} \mathrm{M}\right)$ was then added to the bath and collections were repeated.
Effects of lysyl-bradykinin. Control collections were obtained with or without $2.3 \mu \mathrm{M}$ arachidonic acid in the bath and vehicle (Ringer's bicarbonate plus $2 \%$ bovine serum albumin). Experiments were performed with the perfusion syringe not exposed to light and collections obtained under minimal light exposure. Experimental collections were obtained after adding lysyl-bradykinin $\left(1 \times 10^{-7} \mathrm{M}\right)$ to the bath. Five experiments were conducted with lysyl-bradykinin and no arachidonic acid in the bath and six were conducted with both substances present in the bath.

Effects of cyclic AMP. Control collections were obtained, then 8bromo-cyclic AMP $\left(10^{-5} \mathrm{M}\right)$ dissolved in Ringer's bicarbonate was added to the bath and collections were repeated. After the experimental period, collections were repeated with control bath to assess recovery.

Effects of forskolin. Control collections were made with vehicle (95\% ethanol) present in the bath. Forskolin $\left(10^{-6} \mathrm{M}\right)$ dissolved in vehicle was then added to the bath and collections were repeated. After the experimental period, collections were repeated with control bath to assess recovery.

\section{Reagents}

Arachidonic acid (99\% purity), lysyl-bradykinin, indomethacin, 8-bromocyclic AMP, prostaglandin $E_{2}$ and forskolin were obtained from Sigma Chemical Co. (St. Louis, MO). All reagents were kept frozen for 2 wk as aliquots of stock solutions in the dark under inert gas. Aliquots were thawed as needed without exposure to light or ambient air and dissolved in the solutions for experimentation.

\section{Statistics}

There were three to five measurements of each parameter in a given period for each tubule. The measurements for individual periods in a given tubule were used to calculate the mean value for that period. Data are expressed as means \pm SE. The Student's $t$ test for paired data was used to determine statistical significance. In one protocol, the $t$ test for unpaired data was used to determine statistical significance. Significance was accepted at the 0.05 level.

\section{Results}

Effects of $P G E_{2}$ on acidification. As shown in Table I and Fig. 1 proton secretion, as assessed by bicarbonate reabsorption, decreased significantly from $9.31 \pm 0.88$ to $8.17 \pm 0.88$ $\mathrm{pm} \cdot \mathrm{mm}^{-1} \cdot \mathrm{min}^{-1}(P<0.02)$ after the addition of $10^{-6} \mathrm{M} \mathrm{PGE}_{2}$ in 14 tubules. This was a $12.2 \%$ decrease from control values. In nine tubules, a recovery period was performed. After return to the control bath, $J \mathrm{HCO}_{3}$ and $V_{\mathrm{T}}$ did not return to control values. Perfusion rate was $2.21 \pm 0.11 \mathrm{nl} \cdot \mathrm{min}^{-1}$ and tubular length was $1.45 \pm 0.07 \mathrm{~mm}$. Lumen-positive transepithelial voltage significantly decreased from control values taken $10 \mathrm{~min}$ prior to bath change and $60 \mathrm{~min}$ following $\mathrm{PGE}_{2}$ addition, $28.4 \pm 4.54$ to $19.6 \pm 2.79 \mathrm{mV}(P<0.005)$. Transepithelial voltage fell throughout the exposure period to $\mathrm{PGE}_{2}$. Transepithelial voltage did not recover to control values but stabilized during the recovery period when $V_{\mathrm{T}}$ is compared taken $10 \mathrm{~min}$ before the recovery period with $V_{\mathrm{T}}$ taken 45-90 min following change to control bath, $16.0 \pm 3.73$ to $15.6 \pm 4.28 \mathrm{mV}$.

Effects of indomethacin on acidification. To confirm the observation of inhibition of proton secretion with exogenous $\mathrm{PGE}_{2}$, $125 \mu \mathrm{m}$ indomethacin, a cyclooxygenase inhibitor of endogenous $\mathrm{PGE}_{2}$ formation was evaluated. As shown in Table I and Fig. 2, indomethacin significantly increased proton secretion from $8.05 \pm 0.68$ to $9.19 \pm 0.64 \mathrm{pm} \cdot \mathrm{mm}^{-1} \cdot \mathrm{min}^{-1}$ in seven tubules $(P$ $<0.05$ ). This was a $14.2 \%$ increase from control values. Perfusion rate was $2.42 \pm 0.16 \mathrm{nl} / \mathrm{min}$ and tubular length was $1.48 \pm 0.1$ $\mathrm{mm}$. $V_{\mathrm{T}}$ increased but not significantly from control values 
Table I. Net Bicarbonate Flux and Transepithelial Voltage in Medullary Collecting Tubules

\begin{tabular}{|c|c|c|c|c|c|c|c|c|c|}
\hline \multirow[b]{2}{*}{ Protocol } & \multirow[b]{2}{*}{$\mathbf{n}$} & \multirow[b]{2}{*}{$\begin{array}{l}\text { Perfusion } \\
\text { rate }\end{array}$} & \multirow[b]{2}{*}{$\begin{array}{l}\text { Tubule } \\
\text { length }\end{array}$} & \multicolumn{3}{|l|}{$\mathrm{JHCO}_{3}$} & \multicolumn{3}{|l|}{$V_{\mathrm{T}}$} \\
\hline & & & & C & $\mathbf{E}$ & $\mathbf{R}$ & C & $\mathbf{E}$ & $\mathbf{R}$ \\
\hline & & $n l / m i n$ & $m m$ & & & & & & \\
\hline $\mathrm{PGE}_{2}$ & 14 & $2.21 \pm 0.11$ & $1.45 \pm 0.07$ & $9.31 \pm 0.88$ & $8.17 \pm 0.88^{*}$ & $7.61 \pm 1.22$ & $28.4 \pm 4.54$ & $19.6 \pm 2.79 \ddagger$ & $15.6 \pm 4.28$ \\
\hline Indomethacin & 7 & $2.42 \pm 0.16$ & $1.48 \pm 0.10$ & $8.05 \pm 0.68$ & $9.19 \pm 0.64 \S$ & & $42.1 \pm 5.77$ & $44.9 \pm 7.24$ & \\
\hline Adrenalectomy + indomethacin & 4 & $1.67 \pm 0.02$ & $1.42 \pm 0.15$ & $5.43 \pm 0.75$ & $6.90 \pm 0.93^{*}$ & & $21.1 \pm 3.51$ & $26.2 \pm 4.33$ & \\
\hline \multicolumn{10}{|l|}{ Lysyl-bradykinin with } \\
\hline arachidonic acid & 6 & $2.19 \pm 0.24$ & $1.69 \pm 0.07$ & $8.55 \pm 0.89$ & $8.85 \pm 0.80$ & & $35.0 \pm 3.10$ & $34.5 \pm 3.44$ & \\
\hline \multicolumn{10}{|l|}{ Lysyl-bradykinin without } \\
\hline arachidonic acid & 5 & $3.78 \pm 0.10$ & $1.80 \pm 0.15$ & $8.14 \pm 1.93$ & $8.31 \pm 1.63$ & & $37.0 \pm 6.77$ & $37.2 \pm 5.78$ & \\
\hline All lysyl-bradykinin & 11 & $2.91 \pm 0.20$ & $1.74 \pm 0.08$ & $8.37 \pm 0.94$ & $8.60 \pm 0.81$ & & $35.9 \pm 3.32$ & $35.7 \pm 3.08$ & \\
\hline 8-Bromo-cyclic AMP & 8 & $2.25 \pm 0.09$ & $1.61 \pm 0.06$ & $7.04 \pm 0.66$ & $9.48 \pm 0.74^{\prime \prime}$ & $7.32 \pm 0.58$ & $47.9 \pm 5.19$ & $58.1 \pm 3.91 \ddagger$ & $47.5 \pm 3.57$ \\
\hline Forskolin & 6 & $1.35 \pm 0.05$ & $1.58 \pm 0.14$ & $6.13 \pm 1.21$ & $8.50 \pm 1.03^{\prime \prime}$ & $6.97 \pm 0.95$ & $31.5 \pm 4.34$ & $38.2 \pm 4.59^{*}$ & $21.5 \pm 4.69$ \\
\hline
\end{tabular}

Values are means \pm SEM. ${ }^{*} P<0.02$ control vs. experimental. $¥ P<0.005$ control vs. experimental. $\S P<0.05$ control vs. experimental.

" $P<0.002$ control vs. experimental.

$(42.1 \pm 5.77 \mathrm{mV})$ taken $10 \mathrm{~min}$ prior to indomethacin to peak values taken $45-90 \mathrm{~min}$ following indomethacin addition, $44.9 \pm 7.24 \mathrm{mV}$.

Since indomethacin produced an increase in proton secretion and because desoxycorticosterone acetate (DOCA) pretreatment has been shown to decrease $\mathrm{PGE}_{2}$ production by rabbit cortical collecting tubules in vitro (23), indomethacin in tubules harvested from surgically adrenalectomized rabbits was tested. Our laboratory has shown that proton secretion rates are reduced in $\mathrm{OM}_{\mathrm{i}} \mathrm{CT}$ from adrenalectomized rabbits (14), an observation compatible with but obviously not proof of elevated $\mathrm{PGE}_{2}$ production rates. If indomethacin produced a significantly greater increase in proton secretion by tubules from adrenalectomized rabbits, we would have evidence for enhanced $\mathrm{PGE}_{2}$ production by these tubules. However, no studies to date have been performed to measure $\mathrm{PGE}_{2}$ production rates by medullary collecting ducts in vitro, from adrenalectomized rabbits. As shown in Table $I$ and Fig. 2 proton secretion increased significantly from $5.43 \pm 0.75$ to $6.90 \pm 0.93 \mathrm{pm} \cdot \mathrm{mm}^{-1} \cdot \mathrm{min}^{-1}(P<0.02)$ in

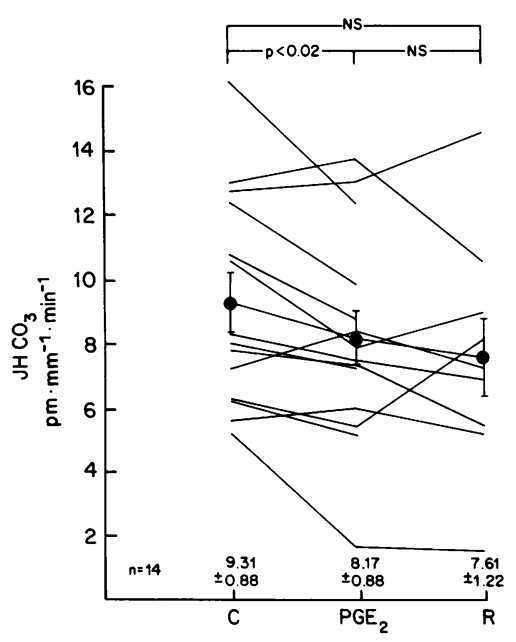

Figure 1. Effect of $10^{-6} \mathrm{M}$ bath $\mathrm{PGE}_{2}$ on medullary collecting duct $J_{\mathrm{HCO}_{3}}$. Values for individual tubules during control $(C), \mathrm{PGE}_{2}$ and recovery $(R)$ periods. Mean $J \mathrm{HCO}_{3} \pm \mathrm{SEM}$ for each period is shown. four tubules from adrenalectomized rabbits following the addition of $50 \mu \mathrm{M}$ indomethacin. This was a $27.1 \%$ increase from control values. Although this increase was greater than in tubules from normal animals exposed to indomethacin, the difference between the increase in $\mathrm{JHCO}_{3}$ in response to indomethacin from normal versus adrenalectomized rabbit tubules was not significantly different. The perfusion rate was $1.67 \pm 0.07$ $\mathrm{nl} \cdot \mathrm{min}^{-1}$ and tubular length was $1.43 \pm 0.15 \mathrm{~mm}$. $V_{\mathrm{T}}$ increased but not significantly when assessed $10 \mathrm{~min}$ before and peak values taken 45-90 min after the addition of indomethacin, 21.1 \pm 3.51 to $26.2 \pm 4.33 \mathrm{mV}$.

Effects of lysyl-bradykinin on acidification. After a demonstrated prostaglandin effect on MCD acidification was observed, and appreciating the fact that lysyl-bradykinin is a potent stimulator of $\mathrm{PGE}_{2}$ production in cultured rabbit papillary collecting duct cells (24), the effect of lysyl-bradykinin on proton secretion was examined.

As shown in Table I and Fig. 3, there was no significant change in proton secretion from control values, $8.37 \pm 0.94$ to $8.60 \pm 0.81 \mathrm{pm} \cdot \mathrm{mm}^{-1} \cdot \mathrm{min}^{-1}$ in 11 tubules. These studies include 6 tubules with $2.3 \mu \mathrm{M}$ arachidonic acid added to the bathing medium to insure adequate substrate for $\mathrm{PGE}_{2}$ production (19) and 5 tubules without arachidonic acid. There was no significant difference between these two groups. The perfusion rate

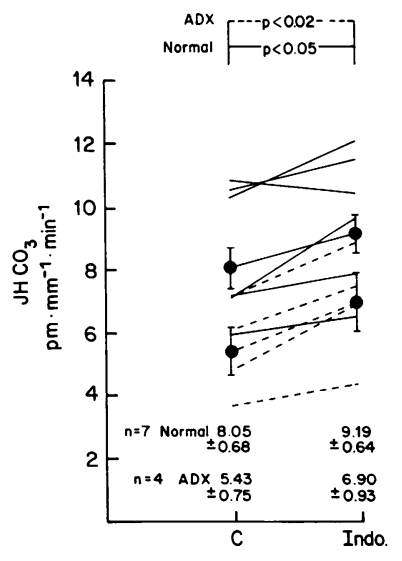

Figure 2. Effect of bath indomethacin (Indo) on medullary collecting duct $\mathrm{JHCO}_{3}$ (see text for concentrations). (-) Normal rabbits. $(---)$ Surgically adrenalectomized rabbits $(A D X)$. 


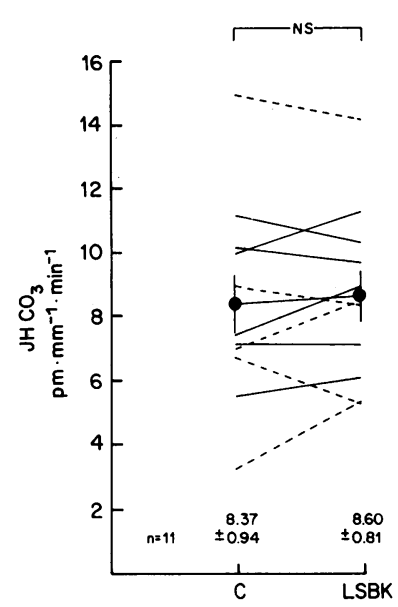

Figure 3. Effect of $10^{-7} \mathrm{M}$ bath lysyl-bradykinin ( $L S B K)$ on medullary collecting duct $\mathrm{JHCO}_{3}$. ( $(-)$ Experiments with $2.3 \mu \mathrm{M}$ arachidonic acid addition to the bath. (- - -) Experiments without arachidonic acid.

was $2.91 \pm 0.20 \mathrm{nl} \cdot \mathrm{min}^{-1}$ and tubule length was $1.74 \pm 0.08 \mathrm{~mm}$. $V_{\mathrm{T}}$ did not change significantly from control values taken 10 min prior to and peak experimental values taken 45-90 min following lysyl-bradykinin addition $35.9 \pm 3.32$ to $35.7 \pm 3.08 \mathrm{mV}$.

Effects of cyclic AMP on acidification. The effects on proton secretion of the common second messenger cyclic AMP were examined. These studies were particularly important because of the observations by Hassid that cyclic AMP inhibits prostaglandin biosynthesis in MDCK cells (25). As shown in Table I and Fig. 4, proton secretion increased significantly from $7.04 \pm 0.66$ to $9.48 \pm 0.74 \mathrm{pm} \cdot \mathrm{mm}^{-1} \cdot \mathrm{min}^{-1}$ following addition of $10^{-5} \mathrm{M}$ 8-bromo-cyclic AMP $(P<0.002)$. This was a $34.5 \%$ increase from control values. During the recovery period proton secretion returned close to control values, $7.32 \pm 0.58 \mathrm{pm} \cdot \mathrm{mm}^{-1} \cdot \mathrm{min}^{-1}$. Perfusion rate was $2.25 \pm 0.09 \mathrm{nl} / \mathrm{min}$ and tubule length was $1.61 \pm 0.06 \mathrm{~mm}$. $V_{\mathrm{T}}$ increased significantly from control values taken 10 min prior to and peak experimental values taken $45-$ 90 min following addition of cyclic AMP (47.9 \pm 5.19 to $58.1 \pm 3.91 \mathrm{mV}, P<0.005)$. $V_{\mathrm{T}}$ likewise fell when taken $10 \mathrm{~min}$ prior to recovery (during cyclic AMP) to peak values taken 4590 min following recovery bath, $56.0 \pm 4.18$ to $47.5 \pm 3.57 \mathrm{mV}$.

Effects of forskolin on acidification. Having demonstrated that exogenous cyclic AMP stimulates proton secretion, the effects of raising endogenous cyclic AMP with the use of forskolin, a known activator of adenylate cyclase (26) were next examined. As shown in Table I and Fig. 5, 10 $0^{-6} \mathrm{M}$ forskolin stimulated proton secretion. Proton secretion was significantly increased frem $6.13 \pm 1.21$ to $8.50 \pm 1.03 \mathrm{pm} \cdot \mathrm{mm}^{-1} \cdot \mathrm{min}^{-1}$ in six tubules $(P<0.002)$. This was a $39 \%$ increase from control values. During the recovery period, proton secretion decreased to $6.97 \pm 0.95$ $\mathrm{pm} \cdot \mathrm{mm}^{-1} \cdot \mathrm{min}^{-1}$. Perfusion rate was $1.35 \pm 0.05 \mathrm{nl} / \mathrm{min}$ and tubular length was $1.58 \pm 0.14 \mathrm{~mm}$. $V_{\mathrm{T}}$ increased significantly from control values taken $10 \mathrm{~min}$ before and peak experimental values taken 45-90 min after forskolin addition, $31.5 \pm 4.34$ to $38.2 \pm 4.59 \mathrm{mV}, P<0.02$. During recovery, $V_{\mathrm{T}}$ decreased from $10 \mathrm{~min}$ prior to recovery (during forskolin) to peak values taken 45-90 min following return to control bath, $25.7 \pm 4.64$ to $21.5 \pm 4.69 \mathrm{mV}$.

\section{Discussion}

The distal nephron is important in the regulation of many urinary solutes. This is especially true with respect to $\mathrm{Na}, \mathrm{K}, \mathrm{Cl}$, and net acid excretion $(1,9,10,12,14,27-30)$. The distal convoluted tubule and the various regions of the collecting duct constitute the specific nephron segments involved. Coincident with our appreciation of the importance of distal nephron transport events, is the impressive documentation that several systemic and intrarenal hormones modulate $\mathrm{Na}, \mathrm{K}, \mathrm{Cl}$, and water transport in the distal nephron $(19,28,31-39)$. The systemic hormones aldosterone and vasopressin thus regulate $\mathrm{Na}, \mathrm{K}, \mathrm{Cl}$, and water movement across portions of the distal nephron $(28,31-$ 34). Similarly, the intrarenal hormones prostaglandin $E_{2}$ and bradykinin have been shown to modulate salt and water transport in the cortical collecting duct $(19,35-39)$.

Although the distal nephron is the final determinant of net acid excretion, information concerning the hormonal regulation of acidification in this region of the kidney is limited. The systemic hormone aldosterone has been shown to influence net acidification in both cortical and medullary collecting tubules $(7-9,14,15,17)$. Also, earlier studies in epithelia analogous to the collecting duct (toad urinary bladder) have demonstrated an effect of vasopressin on proton movement (40), although a physiologic role for vasopressin in acidification is not apparent. There has been no systematic examination of the effects of intrarenal hormones, which are known to be produced and to effect transport in the distal nephron, on acidification.

Our aim was to define whether or not the intrarenal hormones, $\mathrm{PGE}_{2}$ and lysyl-bradykinin and the important mediator of hormonal action, cyclic AMP, played any role in regulating net proton secretion in the $\mathrm{OM}_{\mathbf{i}} \mathrm{CT}$. While we have presented evidence for a role of $\mathrm{PGE}_{2}$ and cyclic $\mathrm{AMP}$, we were unable to detect any action of lysyl-bradykinin.

Several aspects of our studies require discussion. These include $(a)$ the magnitude of the observed changes, $(b)$ the possibility of cyclic AMP and prostaglandin $\mathrm{E}_{2}$ interaction, $(c)$ the cellular mechanism of action of the hormonal agents, $(d)$ the lack of effect of lysyl-bradykinin, and $(e)$ the physiologic significance of our findings.

First, the changes observed in net acidification were small but consistent. $\mathrm{PGE}_{2}$ inhibited proton secretion, while indomethacin stimulated proton secretion. We are not concerned with the lack of reversibility of $\mathrm{PGE}_{2}$ on proton secretion because indomethacin had the expected opposite effect of stimulating proton secretion. The results were also internally consistent with exogenous cyclic AMP stimulating proton secretion and forskolin, a known activator of adenylate cyclase (26), also stimulating proton secretion.

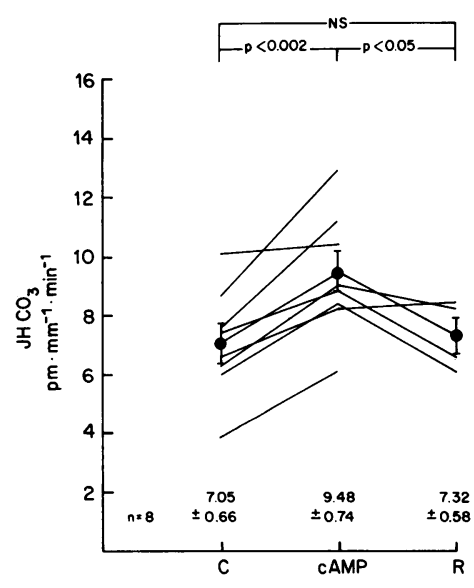

Figure 4. Effect of $10^{-5} \mathrm{M}$ bath cyclic AMP ( $C A M P)$ on medullary collecting duct $\mathrm{JHCO}_{3}$. See Fig. 1 for symbols and format. 


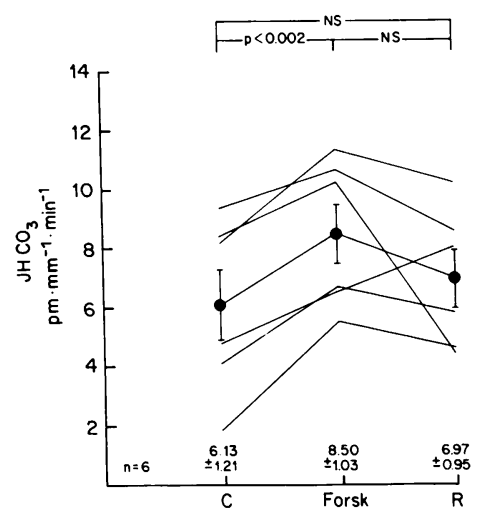

Figure 5. Effect of $10^{-6} \mathrm{M}$ bath forskolin (Forsk) on medullary collecting duct $\mathrm{JHCO}_{3}$. See Fig. 1 for symbols and format.
The changes in net acidification may have been greater if higher doses of the hormones were used. With respect to the concentrations used, however, careful attention was paid to previous studies examining the effects of these same substances on other aspects of collecting duct and medullary tissue transport. Specifically, our use of $\mathrm{PGE}_{2}$ at a concentration of $10^{-6} \mathrm{M}$ is 10-fold greater than the $\mathrm{PGE}_{2}$ concentration required for maximal inhibition of the antidiuretic hormone (ADH) dependent transepithelial voltage in mouse medullary thick ascending limb tubules (41). However, it is identical to the concentration used by Stokes and Kokko (38) to inhibit $\mathrm{Na}$ transport in cortical collecting tubules. Similarly, forskolin at $10^{-6} \mathrm{M}$ is the concentration required to produce a maximal increase in transepithelial voltage of mouse medullary thick ascending limb tubules (42). $10^{-5} \mathrm{M}$ 8-bromo-cyclic AMP is a log lower concentration than that shown by Schuster to stimulate bicarbonate secretion in rabbit cortical collecting tubules (37). Furthermore, $50 \mu \mathrm{M}$ and $125 \mu \mathrm{M}$ indomethacin used in bathing solutions containing both $6 \%$ bovine serum albumin and $5 \% \mathrm{vol} / \mathrm{vol}$ fetal calf serum are two- and fourfold lower concentrations than those used by Kirschenbaum et al. (23) to alter water transport in cortical collecting tubules. In most species, greater than $90 \%$ of indomethacin is bound to the nondiffusible constituents of plasma (43). With both bovine serum albumin and fetal calf serum present in our indomethacin experiments, the free concentration would probably be much lower. Finally, $10^{-7} \mathrm{M}$ lysyl-bradykinin is the concentration shown previously to increase $\mathrm{PGE}_{2}$ production in cultured canine cortical collecting duct cells (44).

The second point we wish to address is the possible interaction between $\mathrm{PGE}_{2}$ and cyclic AMP. Interactions between cyclic AMP and $\mathrm{PGE}_{2}$ have been reported in several different tissues. Hassid found cyclic AMP to inhibit prostaglandin biosynthesis in MDCK cells by modulating the activity of two or more of the enzymes involved in the prostaglandin biosynthetic process (25). Moreover, Teitelbaum and Berl have recently confirmed this inhibition of $\mathrm{PGE}_{2}$ production by cyclic AMP in rat inner medullary cells $(45,46)$. Thus, it appears that in renal medullary tissue, cyclic AMP may reduce $\mathrm{PGE}_{2}$ formation.

Conversely, regulation of adenylate cyclase by prostaglandins has been demonstrated in the adipocyte where $\mathrm{PGE}_{2}$ activates the inhibitory subunit $\left(G_{i}\right)$ of adenylate cyclase leading to decreased intracellular cyclic AMP levels (47). However, in other tissues $\mathrm{PGE}_{2}$ may reduce or increase cyclic AMP levels (48-53). Most recently, in mouse medullary thick ascending limb of Henle (mTALH), Culpepper investigated the mechanism of $\mathrm{PGE}_{2}$ suppression of $\mathrm{ADH}$-dependent $\mathrm{NaCl}$ transport, which is stim- ulated by cyclic AMP. Using forskolin and cholera toxin, $\mathrm{PGE}_{2}$ appeared to inhibit $\mathrm{ADH}$ stimulation of $\mathrm{NaCl}$ transport in the mTALH by an action distal to hormone-receptor interactions, yet proximal to the catalytic subunit of adenylate cyclase (42). Similar to the adipocyte, it appears that $\mathrm{PGE}_{2}$ may suppress the rate of cyclic AMP formation in mouse renal medullary cells by interacting with the $\left(G_{i}\right)$ subunit of adenylate cyclase enzyme. This is further substantiated by the recent work of Schuster. Using pertussis toxin, Schuster found bradykinin-stimulated $\mathrm{PGE}_{2}$ inhibits the ADH effect on water flow by inhibiting cAMP production at the $\left(G_{\mathfrak{i}}\right)$ subunit of adenylate cyclase enzyme in rabbit cortical collecting tubules (54). There is thus evidence for important interactions between cyclic AMP and prostaglandins in several cell lines including renal medullary tissues. Although these specific interactions between cyclic $\mathrm{AMP}$ and $\mathrm{PGE}_{2}$ were not explored in our investigation, the fact that $\mathrm{PGE}_{2}$ inhibited and cyclic AMP stimulated proton secretion in the rabbit medullary collecting duct suggests an interaction may be operative. Cyclic AMP may inhibit $\mathrm{PGE}_{2}$ synthesis and $\mathrm{PGE}_{2}$ may inhibit cyclic AMP formation, accounting for the opposite effects on acidification.

Next, we wish to address the possible mechanisms of action of these hormones. At least three possible mechanisms can be construed. $\mathrm{PGE}_{2}$ and cyclic AMP may act by $(a)$ primarily altering the electrogenic apical membrane proton translocating ATPase, $(b)$ primarily altering electroneutral basolateral chloridebicarbonate exchange, or $(c)$ primarily altering transcellular or paracellular chloride movement.

With only $V_{\mathrm{T}}$ and $\mathrm{JHCO}_{3}$ data, it is difficult to assign a primary mechanism of action for these substances, since it is likely that a primary effect on one process may have rapid secondary effects on the other processes. These processes may be tightly linked within the cell, and $V_{\mathrm{T}}$ and $\mathrm{JHCO}_{3}$ measurements alone cannot allow one to distinguish between primary and secondary effects. Electrophysiologic measurements of basolateral $\mathrm{Cl}^{-}$conductance, apical and basolateral membrane resistances, and intracellular $\mathrm{Cl}^{-}$concentrations are needed to discern the mechanism of action of these hormones.

Although we cannot assign a mechanism of action for these hormones from our data, it would be interesting to speculate that cyclic AMP increases basolateral $\mathrm{Cl}^{-}$conductance as seen in several other epithelia (55-58) $\mathrm{PGE}_{2}$ action may be through interactions with the adenylate cyclase system as described above, to decrease basolateral membrane $\mathrm{Cl}^{-}$conductance. These possibilities, however, would have to be proven with electrophysiologic measurements.

We would next like to comment on the absence of a lysylbradykinin effect. Previous studies in renal tissue have revealed enhanced $\mathrm{PGE}_{2}$ production following exposure to lysyl-bradykinin $(24,44,59)$. In cultured rabbit papillary collecting duct cells and cultured canine cortical collecting tubule cells, bradykinin increased $\mathrm{PGE}_{2}$ formation significantly $(24,44)$. Following lysyl-bradykinin exposure in our experiments, no significant effect on net proton secretion in the $\mathrm{OM}_{\mathrm{i}} \mathrm{CT}$ was found. In previous experiments Schuster et al. (19) added $2.3 \mu \mathrm{M}$ arachidonic acid to the bathing medium to insure optimal conditions for hormone-mediated prostaglandin synthesis. At this concentration of arachidonic acid baseline proton secretion is not affected $\left(8.55 \pm 0.89\right.$ vs. $\left.8.14 \pm 1.95 \mathrm{pm} \cdot \mathrm{mm}^{-1} \cdot \mathrm{min}^{-1}\right)$. Whether or not arachidonic acid was present, however, lysylbradykinin had no significant effect on proton secretion. Studies examining the effect of luminal lysyl-bradykinin were also per- 
formed (not shown) again with no significant effect on proton secretion.

In rat inner medullary cells, Teitelbaum and Berl found only a small increase in $\mathrm{PGE}_{2}$ production $(18.5 \pm 2.4$ to $39.9 \pm 4.4$ $\mathrm{pg} \cdot \mu \mathrm{g}$ protein $\left.{ }^{-1} \cdot \mathrm{h}^{-1}\right)$ following the addition of $10^{-6} \mathrm{M}$ bradykinin (60). Using a log lower concentration $\left(10^{-7} \mathrm{M}\right)$ in our experiments the increase in prostaglandin production might even be less. With such a small rise in $\mathrm{PGE}_{2}$ production due to lysylbradykinin, one might not expect to see the same effect as with exogenous $10^{-6} \mathrm{MPGE}_{2}$. Furthermore, intact tubules and cultured cells may respond differently to known stimulators of prostaglandin biosynthesis. Although $33 \mu \mathrm{M}$ arachidonic acid produces a 250 -fold increase of prostaglandin synthesis in cultured collecting duct cells from rabbits, only a sevenfold increase occurs in intact cortical collecting tubules from the same species (61). In microdissected medullary collecting tubules, Schlondorff found that $10^{-6} \mathrm{M}$ lysyl-bradykinin prevented the fall in $\mathrm{PGE}_{2}$ production they found to occur with time. However, there was variability among tubules (even from the same animal), and in some tubules the fall in $\mathrm{PGE}_{2}$ production with lysyl-bradykinin was greater than in controls (62). It is therefore possible that stimulation of $\mathrm{PGE}_{2}$ production in $\mathrm{OM}_{\mathrm{i}} \mathrm{CT}$ occurs with lysylbradykinin but the increase is too small to alter acidification significantly.

There are thus at least three possible explanations for the failure to demonstrate a lysyl-bradykinin effect on proton secretion. First, as discussed above, $\mathrm{OM}_{\mathrm{i}} \mathrm{CT}$ perfused in vitro may not increase $\mathrm{PGE}_{2}$ production significantly in response to lysylbradykinin. Secondly, in $\mathrm{OM}_{\mathrm{i}} \mathrm{CT}$ perfused in vitro, the process of dissection and manipulation of the tubule for experimentation may stimulate $\mathrm{PGE}_{2}$ production maximally by activating phospholipase (63). Addition of lysyl-bradykinin may not stimulate $\mathrm{PGE}_{2}$ production further in this setting. However, the relatively small absolute increase in proton secretion in response to indomethacin might argue against this. Finally, lysyl-bradykinin may have two separate effects, one to stimulate $\mathrm{PGE}_{2}$ production, thus inhibiting proton secretion, and another to stimulate proton secretion directly resulting in no net effect on proton secretion.

We would like to comment on the possible physiologic significance of our observations. Hormonal effects on net distal nephron acidification must take into consideration the whole distal nephron, i.e., distal convoluted tubule, connecting segment, cortical, medullary and papillary collecting tubules. While we have shown effects on $\mathrm{OM}_{\mathrm{i}} \mathrm{CT}$ acidification, these hormones may have differing effects on other distal segments. With respect to cyclic AMP, this compound has been shown to enhance bicarbonate secretion in the cortical collecting tubule, an effect opposite to that shown in the $\mathrm{OM}_{\mathrm{i}} \mathrm{CT}$. In the turtle bladder and toad bladder, which have the capacity to both secrete and reabsorb bicarbonate, cyclic AMP has been shown to have varied and at times conflicting effects. Cyclic AMP may inhibit proton secretion (64), stimulate proton secretion $(65,66)$, stimulate electrogenic bicarbonate secretion (67), or increase passive bicarbonate permeability (68). It is apparent, therefore, that any effect cyclic AMP might have on net urinary acidification will depend on which distal nephron segment or cell type it is acting upon. This, of course, will be dependent on the specific regulators of cyclic AMP metabolism and may, in addition to $\mathrm{PGE}_{2}$, include a number of well-known hormones such as aldosterone, catecholamines, and parathyroid hormone $(69,70)$.

With respect to $\mathrm{PGE}_{2}$, recent studies are in agreement with our results in the $\mathrm{OM}_{\mathrm{i}} \mathrm{CT}$. Ascer found that $\mathrm{PGE}_{2}$ inhibits turtle bladder proton secretion in a dose-related fashion from $10^{-7}$ to $10^{-4} \mathrm{M}$ (71). Moreover, Kapour used in vivo clearance studies and found increased ammonia production with cyclooxygenase inhibition in both normal and acidotic rats (72). Prostaglandins thus may inhibit ammonia production and proton secretion.

In summary, rabbit $\mathrm{OM}_{\mathrm{i}} \mathrm{CT}$ were studied in vitro to examine the influence of the intrarenal hormones $\mathrm{PGE}_{2}$ and lysyl-bradykinin, and the common second messenger cyclic AMP, on proton secretion. These studies demonstrate that $(a) \mathrm{PGE}_{2}$ inhibits and cyclooxygenase inhibition stimulates proton secretion in the rabbit $\mathrm{OM}_{\mathrm{i}} \mathrm{CT},(b)$ exogenous cyclic $\mathrm{AMP}$ and elevation of endogenous cyclic AMP with forskolin stimulate proton secretion in the rabbit $\mathrm{OM}_{\mathrm{i}} \mathrm{CT}$, and (c) lysyl-bradykinin has no effect on proton secretion in the rabbit $\mathrm{OM}_{\mathrm{i}} \mathrm{CT}$.

\section{Acknowledgments}

The authors wish to thank Ms. Rebecca Aricheta and Ms. Susan Corona for their skillful technical assistance. Dr. Michel Baum and Dr. Dick de Zeeuw provided helpful comments on the manuscript.

This work was supported in part by the National Institutes of Health grants 5-T32-AM07257, 5-R01-AM14677, and 5-R01-AM23091. Dr. Hays was a Burroughs-Wellcome and Hoffmann-La Roche Fellow of the National Kidney Foundation for part of this work.

\section{References}

1. Gottschalk, L. W., W. E. Lassiter, and M. Mylle. 1960. Localization of urine acidification in the mammalian kidney. Am. J. Physiol. 198: 581-585.

2. Steinmetz, P. 1985. Epithelial hydrogen ion transport. In The Kidney: Physiology and Pathophysiology. D. W. Seldin and G. Giebisch, editors. Raven Press, New York. 1441-1458.

3. Koeppen, B., G. Giebisch, and G. Malnic. 1985. In The Kidney: Physiology and Pathophysiology. D. W. Seldin, and G. Giebisch, editors. Raven Press, New York. 1491-1525.

4. Alpern, R. J., D. G. Warnock, and F. C. Rector, Jr. 1985. Renal acidification mechanisms. In The Kidney. F. C. Rector, Jr., and B. Brenner, editors. W. B. Saunders, Philadelphia. 206-249.

5. Lucci, M. S., L. R. Pucacco, N. W. Carter, and T. D. DuBose, Jr. 1982. Evaluation of bicarbonate transport in rat distal tubule: effects of acid base status. Am. J. Physiol. 243:F335-F341.

6. McKinney, T. D., and M. B. Burg. 1977. Bicarbonate transport by rabbit cortical collecting tubules. J. Clin. Invest. 60:766-768.

7. Laski, M. E., and N. A. Kurtzman. 1983. Acidification in the cortical and medullary collecting tubule of the rabbit. J. Clin. Invest. 72: 2050-2059.

8. Lombard, W. E., J. P. Kokko, and H. R. Jacobson. 1983. Bicarbonate transport in cortical and outer medullary collecting tubules. Am. J. Physiol. 244:F289-F296.

9. Stone, D. K., D. W. Seldin, J. P. Kokko, and H. R. Jacobson. 1983. Anion dependence of rabbit medullary collecting duct acidification. J. Clin. Invest. 71:1505-1508.

10. Ullich, K. J., and F. Paparassilou. 1981. Bicarbonate reabsorption in the papillary collecting duct of rats. Pflügers Arch. 389:271-276.

11. Atkins, J. L., and M. B. Burg. 1985. Bicarbonate transport by isolated perfused rat collecting ducts. Am. J. Physiol. 249:F485-F489.

12. Stokes, J. B. 1982. Na and $\mathrm{K}$ transport across the cortical and outer medullary collecting tubule of the rabbit: evidence for diffusion across the outer medullary portion. Am. J. Physiol. 242:F514-F520.

13. Jacobson, H. R. 1984. Medullary collecting duct acidification: effects of potassium, $\mathrm{HCO}_{3}^{-}$concentration, and $\mathrm{PCO}_{2}$. J. Clin. Invest. 74:2107-2114.

14. Stone, D. K., D. W. Seldin, J. P. Kokko, and H. R. Jacobson. 
1983. Mineralocorticoid modulation of rabbit medullary collecting duct acidification: a sodium-independent effect. J. Clin. Invest. 72:77-83.

15. Knepper, M. A., D. W. Good, and M. B. Burg. 1984. Mechanism of ammonia secretion by cortical collecting ducts of rabbits. Am. J. Physiol. 247:F729-F738.

16. Koeppen, B. M., and S. I. Helman. 1982. Acidification of luminal fluid by the rabbit cortical collecting tubule perfused in vitro. Am. J. Physiol. 242:F521-F531.

17. Garcia-Austt, J., D. W. Good, M. B. Burg, and M. A. Knepper. 1985. Deoxycorticosterone-stimulated bicarbonate secretion in rabbit cortical collecting ducts: effects of luminal chloride removal and in vivo acid loading. Am. J. Physiol. 249:F205-F212.

18. Burg, M. B. 1972. Perfusion of isolated renal tubules. Yale $J$. Biol. Med. 45:321-326.

19. Schuster, V. L., J. P. Kokko, and H. R. Jacobson. 1984. Interactions of lysyl-bradykinin and antidiuretic hormone in the rabbit cortical collecting tubule. J. Clin. Invest. 73:1659-1667.

20. Schafer, J. A., S. L. Troutman, and T. E. Andreoli. 1974. Volume absorption, transepithelial potential differences, and ionic permeability properties in mammalian superficial proximal straight tubules. J. Gen. Physiol. 64:582-607.

21. Jacobson, H. R. 1981. Effects of $\mathrm{CO}_{2}$ and acetazolamide on bicarbonate and fluid transport in rabbit proximal convoluted tubules. Am. J. Physiol. 240:F54-F62.

22. Vurek, G., D. Warnock, and R. Corsey. 1975. Measurements of picamole amounts of carbon dioxide by calorimetry. Anal. Chem. 47: 765-767.

23. Kirschenbaum, M. A., A. G. Lowe, W. Trizna, and L. G. Fine. 1982. Regulation of vasopressin action by prostaglandins. Evidence for prostaglandin synthesis in the rabbit cortical collecting tubule. J. Clin. Invest. 70:1193-1204.

24. Grenier, F. C., T. E. Rollins, and W. L. Smith. 1981. Kinininduced prostaglandin synthesis by renal papillary collecting tubule cells in culture. Am. J. Physiol. 241:F94-F104.

25. Hassid, A. 1983. Inhibition of prostaglandin biosynthesis in renal (MDCK) cells by cyclic AMP. Am. J. Physiol. 244:C369-C376.

26. Daly, J. W. 1984. Forskolin, adenylate cyclase and cell physiology: an overview. Adv. Cyclic Nucleotide Protein Phosphorylation Res. 17: 81-89.

27. Boron, W. F., and H. Sackin. Measurement of intracellular ionic composition and activities in renal tubules. Annu. Rev. Physiol. 45:483496.

28. O'Neill, R. G., and S. I. Helman. 1977. Transport characteristics of renal collecting tubules: influences of DOCA and diet. Am. J. Physiol. 233:F544-F558.

29. Stokes, J. B. 1982. Ion transport by the cortical and outer medullary collecting tubule. Kidney Int. 22:473-484.

30. Rocha, A. S., and L. H. Kudo. 1982. Water, urea, sodium, chloride, and potassium transport in the in vitro isolated perfused papillary collecting duct. Kidney Int. 22:485-491.

31. Imai, M., and R. Nukawara. 1982. Function of distal convoluted and connecting tubules studied by isolated nephron fragments. Kidney Int. 22:465-472.

32. Hierholzer, K., and S. Large. 1974. The effects of adrenal steroids on renal function. In International Review of Science, Kidney and Urinary Tract Physiology. K. Thurau, editor. Butterworth, London. 273319.

33. Wingo, C. S., J. P. Kokko, and H. R. Jacobson. 1985. Effects of in vitro aldosterone on the rabbit cortical collecting tubule. Kidney Int. 28:51-57.

34. Grantham, J. J., and J. Orloff. 1968. Effect of $P G_{1}$ on the permeability response of the isolated collecting tubule to vasopressin, adenosine 3',5'-monophosphate, and theophylline. J. Clin. Invest. 47:11541161.

35. Holt, W. F., and C. Lechene. 1981. ADH-PGE 2 interactions in cortical collecting tubule: I. Depression of sodium transport. Am. J. Physiol. 241:F452-F460.
36. Tomita, K., J. J. Pisano, and M. A. Knepper. 1985. Control of sodium and potassium transport in the cortical collecting duct of the rat. Effects of bradykinin, vasopressin, and deoxycorticosterone. J. Clin. Invest. 76:132-136.

37. Schuster, V. L. 1985. Cyclic adenosine monophosphate-stimulated bicarbonate secretion in rabbit cortical collecting tubules. J. Clin. Invest. 75:2056-2064.

38. Stokes, J. B., and J. P. Kokko. 1977. Inhibition of sodium transport by prostaglandin $E_{2}$ across the isolated perfused rabbit collecting tubule. J. Clin. Invest. 59:1099-1104.

39. Kokko, J. P. 1984. Effects of endogenous prostaglandins on cortical collecting tubule ion and water transport. In Prostaglandins and Membrane Ion Transport. P. Braquet, editor. Raven Press, New York. 299-302.

40. Gluck, S., and Q. Al-Awqati. 1980. Vasopressin increases water permeability by inducing pores. Nature (Lond.). 284:631-632.

41. Culpepper, M. R., and T. E. Andreoli. 1983. Interactions among prostaglandin $E_{2}$, andidiuretic hormone, and cyclic adenosine monophosphate in modulating $\mathrm{Cl}^{-}$absorption in single mouse medullary thick ascending limbs of Henle. J. Clin. Invest. 71:1588-1601.

42. Culpepper, M. R., and T. E. Andreoli. 1984. $\mathrm{PGE}_{2}$, forskolin and cholera toxin interactions in modulating $\mathrm{NaCl}$ transport in mouse mTALH. Am. J. Physiol. 247:F784-F792.

43. Hucker, Z. B., A. G. Zacchei, S. V. Cox, D. A. Brodie, and N. H. R. Cartwell. 1966. Studies on the absorption, distribution, and excretion of indomethacin in various species. J. Pharmacol. Exp. Ther. 153:237-249.

44. Garcia-Perez, A., and W. L. Smith. 1983. Use of monoclonal antibodies to isolate cortical collecting tubule cells: AVP induces PGE $_{2}$ release. Am. J. Physiol. 244:C211-C220.

45. Berl, T., and I. Teitelbaum. 1985. Control of prostaglandin synthesis by rat inner medullary collecting tubule cells. Kidney Int. 27:253a.

46. Teitelbaum, I., and T. Berl. 1985. cAMP impairs PGE 2 synthesis in rat inner medullary collecting tubule cells by a phospholipase independent mechanism. Clin Res. 33:500a.

47. Aktories, K., G. Schultz, and K. H. Jakobs. 1980. Regulation of adenylate cyclase activity in hamster adipocytes. Naunyn-Schmiedeberg's Arch. Pharmacol. 312:167-173.

48. Borta, I. L., M. J. P. Adolfs, and W. M. J. A. Ficren. 1984. Cyclic AMP levels and their regulation by prostaglandins in peritoneal macrophages of rats and humans. Adv. Cyclic Nucleotide Protein Phosphorylation Res. 17:615-620.

49. Schlondorff, D., P. Yoo, and B. E. Alport. 1978. Stimulation of adenylate cyclase in isolated rat glomeruli by prostaglandins. Am. J. Physiol. 235:F458-F464.

50. Simond, B., H. Kather, and B. Kommerall. 1980. Activation of human colonic mucosal adenylate cyclase by prostaglandins. Adv. Prost. Thromboxane Res. 8:1617-1620.

51. Lapetina, E. G., C. J. Schritges, K. Chandrabose, and P. Cuatrecasas. 1977. Cyclic adenosine $3^{\prime}-5^{\prime}$ monophosphate and prostacyclin inhibit phospholipase activity in platelets. Biochem. Biophys. Res. Commun. 76:828-835.

52. Malmstein, C., E. Granström, and B. Samuelson. 1976. Cyclic AMP inhibits synthesis of prostaglandin endoperoxide $\left(\mathrm{PGG}_{2}\right)$ in human platelets. Biochem. Biophys. Res. Commun. 68:569-576.

53. Schafer, A. I., S. Levine, and R. I. Handin. 1980. Regulation of platelet arachidonic acid oxygenation by cyclic AMP. Blood. 56:853857.

54. Schuster, V. L. 1985. Mechanism of bradykinin, ADH and cAMP interaction in rabbit cortical collecting duct. Am. J. Physiol. 249:F645F653.

55. Nagel, W., and P. Reinach. 1980. Mechanism of stimulation by epiniphrine of active transepithelical $\mathrm{Cl}$ transport in isolated frog cornea. J. Membr. Biol. 56:73-79.

56. Welsh, M. J., P. L. Smith, and R. A. Frizzel. 1982. Chloride secretion by canine tracheal epithelium. II. The cellular electrical potential profile. J. Membr. Biol. 70:227-238. 
57. Petersen, K.-U., and L. Ruess. 1983. Cyclic AMP induced chloride permeability in the apical membrane of Necturus gallbladder epithelium. J. Gen. Physiol. 81:705-729.

58. Schlatter, E., and R. Greger. 1984. Mechanism of a AMP-stimulation of active $\mathrm{NaCl}$ reabsorption in the isolated perfused medullary thick ascending limb of Hele's loop. Pflügers Arch. 400(Suppl.):R22 (Abstr.)

59. Schwartzman, M., F. Liberman, and A. Raz. 1981. Bradykinin and angiotensin II activation of arachidonic acid deacylation and prostaglandin $\mathrm{E}_{2}$ formation in rabbit kidney. J. Biol. Chem. 256:2329-2333.

60. Teitelbaum, I., A. Wolf, and T. Berl. 1984. Control of prostaglandin (PG) synthesis in cultured rat inner medullary collecting tubule (RIMCT) cells: the role of calcium (Ca). Abstracts of the IX International Congress of Nephrology, 464A.

61. Currie, M. G., B. R. Cole, K. DeSchryver-Kecskemeti, and P. Needleman. 1983. Cell culture of renal epithelium derived from rabbit microdissected cortical collecting tubules. Am. J. Physiol. 244:F724F728.

62. Schlondorff, D., J. A. Satriano, and G. J. Schwartz. 1985. Synthesis of prostaglandin $E_{2}$ in different segments of isolated collecting tubules from adult and neonatal rabbits. Am. J. Physiol. 248:F134-F144.

63. Flower, R. J., and G. J. Blackwell. 1976. The importance of phospholipase $\mathrm{A}_{2}$ in prostaglandin biosynthesis. Biochem. Pharmacol. 25:285-291.
64. Lief, P. D., B. F. Mutz, and N. Bank. 1979. Effect of cyclic AMP on hydrogen ion secretion by turtle urinary bladder. Kidney Int. 16:103112.

65. Frazier, L. W. 1976. Effects of parathyroid hormone on $\mathrm{H}^{+}$and $\mathrm{NH}_{4}^{+}$excretion in toad urinary bladder. J. Membr. Biol. 30:187-196.

66. Spar, B., E. Kelepouris, R. Garrick, and Z. S. Agus. 1984. Isoproterenol and cAMP stimulation of $\mathrm{H}^{+}$secretion in toad bladder. Kidney Int. 25:239a.

67. Satake, N., J. H. Durham, G. Ehrenspeck, and W. A. Brodsky. 1983. Active electrogenic mechanisms for alkali and acid transport in turtle bladders. Am. J. Physiol. 244:C259-C269.

68. Sabatini, S. 1985. Effect of cyclic AMP on acidification in the isolated turtle bladder. Kidney Int. 27:25-30.

69. Liddle, G. W., and J. G. Herdman. 1971. Cyclic adenosine monophosphate as a mediator of hormone action. N. Engl. J. Med. 285: 560-566.

70. Robinson, G. A., R. W. Butcher, and E. W. Sutherland. 1971. Cyclic AMP. Academic Press, New York.

71. Ascer, K., I. Lowenstein, B. Mutz, M. Schwartzman, and P. Lief. 1984. Prostaglandin $\mathrm{E}_{2}$ inhibits $\mathrm{H}^{+}$secretion in the turtle urinary bladder. Kidney Int. 25:228a.

72. Kapour, S., T. Beck, R. G. Narins, and E. R. Jones. 1984. Prostaglandins modulate total ammonia production. Kidney Int. 25:233a. 